\title{
Antibiotic Resistance of Aeromonas hydrophila Strains Isolated from Karasu Stream (Sinop/Turkey)
}

\author{
Serdar Bektas, and Sefa Iscimen
}

\begin{abstract}
The susceptibilities of 3 Aeromonas hydrophila strains isolated from Karasu stream (Sinop/Turkey), were tested by the Kirby-Bauer disk method for resistance to ten antibiotics. All of the strains were found resistant to Amoxycillin and Cefaclor. The extensive and misuse of antimicrobial drugs accelerates the emergence of drug-resistant strains. Antibiotic resistance is a global concern, threatening our ability to treat common infectious diseases both in human and animal.
\end{abstract}

Keywords_-Aeromonas hydrophila, disk diffusion, resistance.

\section{INTRODUCTION}

A EROMONAS hydrophila is a heterotrophic, Gram-negative, rod-shaped, motile bacterium It can survive in aerobic and anaerobic environments also present in numerous fresh or brackish water habitats worldwide, currently has the status of a foodborne pathogen causing zoonotic diseases in fish and numerous terrestrial vertebrates including humans [1]-[2].

Antimicrobial resistance is resistance of a microorganism to an antimicrobial drug that was originally effective for treatment of infections caused by it. The evolution of resistant strains is a natural phenomenon that occurs when microorganisms replicate themselves erroneously or when resistant traits are exchanged between them [3]. Antibiotics, have been successfully used in the treatment of bacterial diseases for many years. Over time, however, many infectious organisms have adapted to the antibiotics designed to kill or stop the growth of them, making the products less effective.

An important task of the clinical microbiology laboratory is the performance of antimicrobial susceptibility testing of significant bacterial isolates. The goals of testing are to detect possible drug resistance in common pathogens and to assure susceptibility to drugs of choice for particular infections [4]. An effective treatment against to infectious diseases, requires antimicrobial susceptibility experiments to evaluate the susceptibility and resistance development to antimicrobial agents [5].

This study was carried out to determine the in vitro antimicrobial susceptibilities of A.hydrophila isolates by using

Serdar Bektas, and Sefa Iscimen are with Sinop University Faculty of Fisheries and Aquaculture, Turkey. a disc diffusion method which is most popular for routine testing.

\section{MATERIALS AND METHODS}

Water samples in this study were collected from 3 different sites along the stream during wet season, samples were taken $10 \mathrm{~cm}$ below the water surface and collected in $150 \mathrm{ml}$ glass screw-capped containers than transported to the laboratory in ice boxes and analyzed within 24 hours [6]-[7].

$100 \mu \mathrm{l}$ of the all samples were plated on McConkey agar and incubated 24 hours at $370 \mathrm{C}$ after incubation, oxidase, catalase and indole positive samples selected and API-20NE system (bioMérieux) were utilized for identification of Aeromonas species. Various rapid test systems have commercially been developed in identifying the bacterial isolates. The API system used for the identification of the Aeromonas hydrophila in the present study is one of these. [8]-[9].

The following antimicrobial susceptibility test discs with their concentrations shown in parentheses were used to determine antimicrobial susceptibility of the bacterial isolates; Amoxicillin (10 $\mu \mathrm{g})$, Cefaclor $(30 \mu \mathrm{g})$, Chloramphenicol

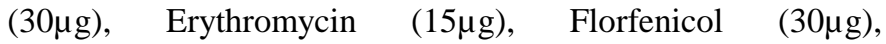
Furazolidone $(100 \mu \mathrm{g})$, Tetracycline $(30 \mu \mathrm{g})$, Oxolinic Acid

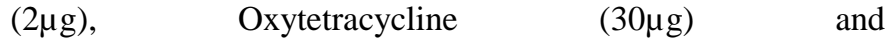
Trimethoprim/Sulfamethoxazole ( $25 \mu \mathrm{g})$

The disc diffusion assay was carried out according to the recommendations of the National Committee for Clinical Laboratory Standards (NCCLS) [10]. Basically bacteria were harvested after 48 hours growth on Trypticase soy agar at 35 0C and suspended in sterile $0.85 \%$ saline and streaked on Mueller-Hinton agar (Difco) using a cotton swab [11]. Plates were incubated at $350 \mathrm{C}$ for 48 hours. Zones of inhibition formed around the discs were measured, and antimicrobial sensitivity was assayed from the length of the diameter of the zones (in $\mathrm{mm}$ ). The zone radius was actually scaled from the centre of the antibiotic disc to the end of the clear zone where bacteria could be seen growing. Zone diameters were interpreted as susceptible, intermediate and resistant according to the manufacturer's instructions [12].

\section{RESULT AND DISCUSSION}

Among the 3 A.hydrophila isolates recovered from stream samples, all of the strains were found resistant to $\beta$-lactam antibiotics such as amoxicillin and cefaclor, an intermediate reaction with erythromycin is also occurred (Table I). Similar 
findings with $\beta$-lactam antibiotics, reported by several researchers [13]-[14]-[15].

TABLE I: INHIBATION ZONE DIAMETERS FOR A. HYDROPHILA

\begin{tabular}{lll}
\hline Antibiotic $(\mu \mathrm{g} /$ disc $)$ & $\begin{array}{l}\text { Inhibation } \\
\text { Zone }(\mathrm{mm})\end{array}$ & Sensitivity \\
\hline Amoxicillin $(10 \mu \mathrm{g})$ & 6 & $\mathrm{R}$ \\
Cefaclor $(30 \mu \mathrm{g})$ & 6 & $\mathrm{R}$ \\
Chloramphenicol $(30 \mu \mathrm{g})$ & 32 & $\mathrm{~S}$ \\
Erythromycin $(15 \mu \mathrm{g})$ & 18 & $\mathrm{I}$ \\
Florfenicol $(30 \mu \mathrm{g})$ & 31 & $\mathrm{~S}$ \\
Furazolidone $(100 \mu \mathrm{g})$ & 23 & $\mathrm{~S}$ \\
Tetracycline $(30 \mu \mathrm{g})$ & 25 & $\mathrm{~S}$ \\
Oxolinic Acid $(2 \mu \mathrm{g})$ & 29 & $\mathrm{~S}$ \\
Oxytetracycline $(30 \mu \mathrm{g})$ & 25 & $\mathrm{~S}$ \\
Trimethoprim/Sulfamethoxazole & 21 & $\mathrm{~S}$ \\
$(25 \mu \mathrm{g})$ & & \\
\hline
\end{tabular}

R: Resistant, S: Susceptible, I: Intermediate

ß-lactams belong to a family of antibiotics which is characterized by a ß-lactam ring which is necessary for the activity, results in the inactivation of a set of transpeptidases that catalyze the final cross-linking reactions of peptidoglycan synthesis, bacterial resistance to beta-lactam antibiotics can be achieved by any of three strategies: the production of betalactam-hydrolyzing beta-lactamase enzymes, the utilization of beta-lactam-insensitive cell wall transpeptidases, and the active expulsion of beta-lactam molecules from Gram-negative cells by way of efflux pumps [16].

Resistance of a microorganism to an antimicrobial drug is a global concern, because this resistance threatens the effective prevention and treatment of the infections caused by both gram-positive and gram-negative pathogens. Incase of an infectious disease caused by bacteria, prior to an antibiotic treatment, susceptibility testing is so important for to prevent the antibiotic resistance and also antibiotics only should be used if absolutely necessary.

\section{REFERENCES}

[1] Y. W. Ye, T. F. Fan, H. Li. J. F. Lu. H. Jiang. W. Hu, and Q. H. Jiang, "Characterization of Aeromonas hydrophila from hemorrhagic diseased freshwater fishes in Anhui Province, China,” International Food Research Journal, vol. 20(3), pp. 1449-1452, January 2013.

[2] L. İ. Jing, X. L. Zhang, Y. J. Liu, and C. P. Lu, "Development of an Aeromonas hydrophila infection model using the protozoan Tetrahymena thermophile ," FEMS Microbiol. Lett., vol. 316, pp. 160-168, December 2010.

[3] "Antimicrobial resistance Fact sheet N¹94". who.int. April 2014. Retrieved March 2015.

[4] J. H. Jorgensen, and M. J. Ferraro, "Antimicrobial susceptibility testing: a review of general principles and contemporary practices," Medical Microbiology, vol. 49, pp. 1749-1755, December 2009. http://dx.doi.org/10.1086/647952

[5] A. Thyssen, and F. Ollevier, "In vitro antimicrobial susceptibility of Photobacterium damselae subsp. piscicida to 15 different antimicrobial agents,” Aquaculture, vol. 200 (2001), pp. 259-269, December 2000.

[6] T.A. Ayandiran, A.A. Ayandele, S.O. Dahunsi, and O.O. Ajala, "Microbial assessment and prevalence of antibiotic resistance in polluted Oluwa River, Nigeria," Egyptian Journal of Aquatic Research, vol. 40, pp. 291-299, October 2014. http://dx.doi.org/10.1016/j.ejar.2014.09.002

[7] A. Karafistan, and F. A. Colakoglu, "Physical, chemical and microbiological water quality of the Manyas lake, Turkey,” Mitigation and Adaptation Strategies for Global Change, vol. 10, pp. 127-143, December 2003.

http://dx.doi.org/10.1007/s11027-005-7835-x

[8] I. Stojanov, N. Plavsa, D. Stojanovic, R. Ratajac, J.R. Raduvolıc, I. Pusic, and M. Kapetanov, "Susceptibility of Aeromonas hydrophila 1solates ta antimicrobial drugs, " Lucrări Stiintifice Medicină Veterinară, vol. XLIII (1), pp. 132-136, November 2010.

[9] M. B. Awan, M. M. Ahmed, A. Bari, and M. S. Anwar, "Biochemical characterization of the Aeromonas species isolated from food and environment,” Pak. J. Physiol., vol. 1(1-2), pp. 10-21, June 2005.

[10] National Committee for Clinical Laboratory Standards, 1987. Performance standards for antimicrobial disc and dilution susceptibility tests for bacteria isolated from animals; Tentative standard M31-T. NCCLS, Pennsylvania, USA.

[11] A.W. Bauer, W.M.M. Kirby, J.C Sherris, and M. Turck. "Antibiotic susceptibility testing by a standardized single disc method," American Journal of. Clinical Pathology, vol. 45, pp. 493-496, April 1966.

[12] D. Saha, and J. Pal, " In vitro antibiotic susceptibility of bacteria isolated from EUS-affected fishes in India," Letters in Applied. Microbiology vol. 34(5) , pp 311-316, May 2002. http://dx.doi.org/10.1046/j.1472-765X.2002.01124.x

[13] M.J. Saavedr, S.G. Novais, A. Alves, P. Rema, M. Tacão, A. Correia, and A.M.Murcia, "Resistance to $\beta$-lactam antibiotics in Aeromonas hydrophila isolated from rainbow trout (Oncorhynchus mykiss)," International Microbiology, vol. 7, pp. 207-211, july 2004.

[14] S.N. Njeru, S.Kiruki, M. Limo, M.J. Mbala, E.N.N. Njagi, P.O.Okemo, and L. Nathan, "Antimicrobial resistance and plasmid profiles of Aeromonas hydrophila isolated from River Njoro, Kenya," African Journal of Biotecnology, vol.11(96), pp. 16284-16290, November 2012.

[15] R. Zemalman, C. Gonzalez, M.A. Mondaca, J. Silva, C. Merino, and M. Dominguez, "Resistance to beta-lactam antibiotics." J. Antimicrob. Chemother, vol. 14(6), pp. 575-579, December 1984. http://dx.doi.org/10.1093/jac/14.6.575

[16] M. S. Wilke, A. L. Lovering, and N. C. Strynadka, "Beta-lactam antibiotic resistance: a current structural perspective,” Curr. Opin. Microbiol., vol. 8(5), pp. 525-533, October 2005. http://dx.doi.org/10.1016/j.mib.2005.08.016 